\title{
Obtenção e caracterização físico-química de farinha do caroço de abacate para adição em bolos
}

\section{Obtention and physical-chemical characterization of avocado seed flour in addition to cakes}

\author{
1 Lais Sene Freitas lala_sene@hotmail.com \\ 1 Caroline Sayuri Yamashita Dutra \\ 1 Mabelle Biancardi Oliveira de Medeiros \\ 1 Alba Regina Pereira Rodrigues \\ 1 Diana Clara Nunes Lima
}

1 Centro Federal de Educação Tecnológica Celso Suckow da Fonseca (CEFET/RJ)

\section{RESUMO}

No Brasil, em 2010, foram produzidas 152.181 toneladas de abacates, porém apenas a polpa é aproveitada para fins alimentícios e a extração de óleos para as indústrias farmacêuticas e de cosméticos, sendo cerca de 42.000 toneladas consideradas resíduos (cascas e caroço) que são descartados, representando cerca de $25 \%$ do peso total do fruto. Com o intuito de aumentar o aproveitamento do abacate, obteve-se uma farinha a partir de seu caroço, a fim de reduzir o desperdício, para posterior aplicação em massas de bolo. Preparou-se uma formulação padrão de bolo de chocolate (apenas com farinha de trigo) e duas formulações utilizando-se a farinha de abacate (em diferentes proporções) com propósito de enriquecer o alimento. As análises físico-químicas foram realizadas para obter a composição centesimal da farinha, que apresentou maior teor de carboidratos, lipídeos e cinzas, comparado à farinha de trigo convencional. Realizou-se a análise microbiológica para quantificação de coliformes totais e fecais, apresentando-se ausências. Ao realizar a análise de comparação no crescimento do bolo, aplicando-se o teste de Tukey, verificou-se que não possuía diferença significativa $(a=0,05)$. A análise sensorial foi aplicada para verificar o nível de aceitação dos provadores quanto aos atributos aparência, aroma, cor, sabor, textura e avaliação global, obtendo notas superiores a 6,45 , em escala hedônica de nove pontos, indicando uma boa aceitação. Logo, o bolo desenvolvido apresentou propriedades sensoriais aceitáveis, demostrando que os níveis de substituição de farinha de abacate usado foram bem aceitos pelos provadores, demonstrando que se trata de um produto com aceitação comercial satisfatória.

\section{Palavras-chave:}

Análises físico-químicas. Farinha do caroço de abacate. Aproveitamento de resíduo.

\begin{abstract}
In 2010, were produced 152,181 tons of avocado in Brazil but only the pulp was used for food purposes. On the other hand, extraction of avocado oils was performed for both pharmaceutical and cosmetics industries being that around 42,000 tons were considered waste (peels and stones) and it represented about $25 \%$ of the total weight of the fruit. In order to increase the use of avocado, a flour was obtained from its seed to reduce waste, for later application in cakes. For comparison purpose, a standard formulation of chocolate cake (only with wheat flour) and two formulations containing only avocado flour (in different proportions) in order to enrich the food were prepared. Physical-chemical analyzes were performed to obtain the proximate composition of the flour, which had higher content of carbohydrates, lipids and ashes in comparison to conventional wheat flour. Microbiological analysis was performed to quantify total and fecal coliforms, and it showedabsences. The comparisonanalysis on cakegrowth was also performed, applying the Tukey test and found that there was no significant difference $(a=0.05)$. Sensory analysis was applied to see the level of acceptance of the tasters regarding the attributes appearance, aroma, color, flavor, texture and overall assessment, obtaining scores above 6.45 , on a hedonic scale of nine points, indicating a good acceptance. Therefore, the cake developed had acceptable sensory properties, showing that the levels of substitution of avocado flour used were well accepted by the tasters, being a product with satisfactory commercial acceptance.
\end{abstract}

\section{Keywords:}

Physical-chemical analyses. Avocado seed flours. Use of waste.

\section{Como você deve citar?}

FREITAS, Lais Sene et al. Obtenção e caracterização físico-química de farinha do caroço de abacate para adição em bolos. Cadernos UniFOA, Volta Redonda, n. 45, p. 35-43, abril 2021. 


\section{INTRODUÇÃO}

O abacate é um fruto cultivado em quase todas as regiões tropicais e subtropicais do mundo, possuindo vitaminas lipossolúveis, proteínas e elevados teores de potássio e ácidos graxos insaturados. No entanto, a polpa do abacate é consumida e não há o aproveitamento da casca e do caroço como alimento. Seu caroço representa em média um quarto do peso total do fruto e compõe uma fonte interessante para ser explorada e criar produtos, com substâncias de interesse nutricional e comercial, como os ácidos graxos, substâncias antioxidantes capazes de combater os radicais livres e substâncias antimicrobianas e antibióticas. (MELO et al., 2012).

É importante a utilização de cascas, folhas, talos e caroços, pois o aproveitamento desses resíduos reduz o desperdício e torna possível a exploração e o desenvolvimento de novos produtos, visando meIhorar a qualidade da alimentação da população (MELO et al., 2012; GUIMARÃES, CAPOBIANGO, 2017).

Diversos estudos atualmente envolvem o aproveitamento de vegetais e têm recebido destaque e atenção. Os enfoques são diferentes para os tipos de aproveitamento, porém percebe-se a preocupação em minimizar o desperdício, a insegurança alimentar e a preservação do meio ambiente. 0 reaproveitamento desses resíduos de vegetais pode ser utilizado para a produção de farinhas e, consequentemente, para elaboração de bolos e biscoitos, a partir desses subprodutos (RORIZ, 2012).

De acordo com a legislação, farinhas são os produtos obtidos de partes comestíveis de uma ou mais espécies de cereais, leguminosas, frutos, sementes, tubérculos e rizomas por moagem e/ou outros processos tecnológicos considerados seguros para produção de alimentos (ANVISA, 2005). De acordo com a Agência Nacional de Vigilância Sanitária (ANVISA), considera-se alimento enriquecido, quando se adiciona um ou mais nutrientes essenciais contidos naturalmente ou não no alimento, com o objetivo de reforçar o seu valor nutritivo e/ou corrigir deficiências demonstradas em um ou mais nutrientes na alimentação da população (ANVISA, 1998).

Portanto, este estudo teve por objetivo produzir uma farinha a partir do caroço de abacate e realizar análises físico-químicas e microbiológicas para se obter a composição centesimal e qualidade microbiológica do produto, bem como produzir diferentes formulações de bolo de chocolate com substituição parcial da farinha de trigo pela farinha de abacate, além de realizar a análise sensorial para verificação de sua aceitação.

\section{METODOLOGIA}

\subsection{Procedimento geral}

Foram adquiridos 57 abacates (Persea americana Mill.) com um produtor rural do município de Valença - RJ, transportados em sacos plásticos até o Laboratório de Produtos de Origem Vegetal, do Centro Federal de Educação Tecnológica Celso Suckow da Fonseca (CEFET/RJ), Campus Valença. Posteriormente, os produtos foram lavados em água corrente, sendo sanitizados em água clorada a 100 ppm de cloro ativo, por 15 minutos.

\subsection{Produção da Farinha}

Realizou-se o descascamento e corte manual dos caroços, com posterior trituração e moagem, por meio de processador e liquidificador, para produção da farinha de caroço de abacate. 0 caroço de abacate foi desidratado em uma secadora de frutas, com circulação de ar, a $60^{\circ} \mathrm{C}$ por 5 horas. Após 
a secagem, o produto foi novamente triturado para que as partículas adquirissem a granulometria indicada para farinhas.

A farinha foi armazenada em embalagem plástica a vácuo e congelada para que diminuíssem as reações de oxidação e permanecesse conservada até a realização das análises.

\subsubsection{Análises da Farinha:}

\section{Análise da composição centesimal}

As determinações de proteínas, carboidratos, lipídeos, cinzas e umidade, realizadas em triplicatas, foram realizadas de acordo com os métodos preconizados pelo Instituto Adolfo Lutz, 2005 (PADILHA et al., 2008). As análises foram realizadas no Laboratório de Físico-Química do CEFET/RJ, Campus Valença.

\section{Análise Microbiológica}

As análises microbiológicas foram realizadas no Laboratório de Microbiologia do CEFET/RJ, Campus Valença, de acordo com os padrões estabelecidos pela legislação brasileira, emitidos pela Agência Nacional de Vigilância Sanitária (BRASIL, 2001) e executada conforme a Instrução Normativa $n^{\circ} 62$ (BRASIL, 2003).

Para a realização da análise de coliformes, foi pesada $25 \mathrm{~g}$ de cada amostra e colocadas de maneira asséptica em um erlenmeyer com $225 \mathrm{~mL}$ de água peptonada a 0,1\%, sendo diluída até 10-3. Foram inoculadas em triplicatas em tubos com $9 \mathrm{~mL}$ de caldo lauril sulfato triptose (LST), alíquotas de $1 \mathrm{~mL}$ de cada diluição e, dentro de cada tubo, havia um tubo de Duhran.

Os tubos foram incubados por 24 a 48 horas em uma temperatura de $36^{\circ} \mathrm{C}$, sendo esse processo denominado de fase presuntiva. A fase presuntiva é baseada na inoculação da amostra em caldo LST, na qual, a partir da presença de gás e/ou turvação nos tubos de Durhan que são produzidas devido à fermentação da lactose presente no meio, determina-se a presença de coliformes (BRASIL, 2003).

\subsection{Produção do Bolo:}

O bolo foi produzido com o intuito de substituir parte da farinha de trigo por farinha de caroço de abacate. Elaborou-se uma formulação padrão com $100 \%$ de farinha de trigo e outras duas formulações com porcentagens diferentes de farinha do caroço de abacate.

As porcentagens dos ingredientes foram definidas utilizando-se como base o peso total da farinha de trigo como $100 \%$, como descritas na Tabela 1: 
Tabela 1 - Formulações dos bolos.

\begin{tabular}{cccc}
\hline Ingredientes & Padrão & Formulação 1 & Formulação 2 \\
\hline Farinha de trigo & $100 \%$ & $90 \%$ & $80 \%$ \\
\hline Farinha de caroço de abacate & - & $10 \%$ & $20 \%$ \\
\hline Açúcar & $96 \%$ & $96 \%$ & $96 \%$ \\
\hline Ovo & $54 \%$ & $54 \%$ & $54 \%$ \\
\hline Margarina & $45 \%$ & $45 \%$ & $45 \%$ \\
\hline Leite fluido & $43 \%$ & $43 \%$ & $20 \%$ \\
\hline Chocolate em pó (100\% cacau) & $20 \%$ & $20 \%$ & $3 \%$ \\
\hline Fermento Químico & $3 \%$ & $3 \%$ & $1 \%$ \\
\hline Essência de baunilha & $1 \%$ & $1 \%$ & $20 \%$ \\
\hline
\end{tabular}

Fonte: autores

Para elaboração do bolo, foi adicionado o açúcar e a margarina em uma batedeira e batido até obter um creme homogêneo. Adicionou-se os ovos junto com a essência de baunilha, mantendo-se a batedeira ligada. Em seguida, adicionou-se o leite, e, após a massa estar homogeneizada, adicionou-se as farinhas, o chocolate em pó e o fermento químico. A mistura continuou sendo batida para nova homogeneização. Em formas untadas e polvilhadas com farinha de trigo, foi despejada a mistura até a metade da forma. Levou-se ao forno industrial para assar, na temperatura de $160^{\circ} \mathrm{C}$, por, aproximadamente, 30 minutos.

\subsubsection{Análises dos Bolos:}

\section{Análise do crescimento}

Os ingredientes utilizados para a produção dos bolos apresentam algumas funções específicas como fornecer força e estrutura ao bolo (farinha e ovos), abrir a textura (açúcares, gorduras e fermento químico) e fechar a textura e reduzir a leveza (água e leite). Para verificar se o tipo e porcentagem de farinha utilizada interferiu diretamente no crescimento, foi realizada análise da diferença no crescimento dos bolos por meio da medição da altura da massa antes e após a assadura, uma vez que o tamanho das formas é o mesmo.

\section{Análise Sensorial}

A análise sensorial foi realizada no Laboratório de Análise Sensorial do CEFET/RJ, Campus Valença. Participaram dos testes de aceitação 60 consumidores, sendo 38,3\% homens e $61,7 \%$ mulheres, com idade entre18 e 53 anos.

Antes da análise sensorial, todos os consumidores leram e assinaram o Termo de Consentimento Livre e Esclarecido (TCLE), aprovado pelo Comitê de Ética em Pesquisa em Seres Humanos - CAAE 06773118.4 .0000 .5237$. 
As amostras foram fatiadas, dividindo-as em pedaços de $2 \mathrm{~cm}$, sendo esse processo realizado para os três diferentes bolos. As amostras foram codificadas com um número de três dígitos e servidas individualmente junto a um copo com água, uma ficha sensorial, lápis e borracha. A ordem de apresentação das amostras obedeceu a um delineamento de blocos completos casualizados, para que não houvesse qualquer influência no resultado.

Em cabines individuais, iluminadas com luz branca, foi pedido a cada consumidor para observar e experimentar as amostras e, em seguida, responder à ficha sensorial de aceitação, escala hedônica, verbal estruturada, que variava desde "desgostei muitíssimo" (1) até "gostei muitíssimo" (9), em relação aos atributos de aparência, aroma, cor, sabor, textura e avaliação global.

\section{Análise estatística}

Todos os experimentos foram realizados em triplicatas e os resultados foram obtidos através da análise de variância (ANOVA), seguido do teste de Tukey $(\alpha<0,05)$ com auxílio do programa computacional STATISTICA 11.0 .

\section{RESULTADOS E DISCUSSÕES}

O caroço de abacate possuía uma coloração salmão claro e, ao ser cortado e processado, obteve uma coloração laranja escuro, sendo esse escurecimento não desejável. A reação de escurecimento enzimático ocorreu devido à enzima polifenoloxidase (PPO), que catalisou a oxidação dos compostos fenólicos do abacate, produzindo, ao serem cortados, pigmentos escuros. Devido à reação ocorrida, é possível que a farinha possa ter sofrido alterações não só na coloração, mas também perdas e mudanças na textura, no sabor e no odor (SARAIVA et al., 2010; SOUZA, LEÃO, 2012).

\subsection{Análise da composição centesimal}

Os resultados da composição centesimal da farinha de caroço de abacate obtidos nas análises físico-químicas estão apresentados na Tabela 2, em comparação aos teores médios da farinha de trigo (TBCA, 2017). Foram expressos valores médios obtidos em porcentagem. Após ser processada, antes de ser seca, a farinha de caroço de abacate apresentava umidade de, aproximadamente, $56 \%$.

Tabela 2 - Composição nutricional da farinha do caroço de abacate comparada à composição da farinha de trigo

\begin{tabular}{ccc}
\hline \multirow{2}{*}{ Composição } & \multicolumn{2}{c}{ Teores Médios (\%) } \\
\cline { 2 - 3 } & Farinha do caroço de abacate & Farinha de trigo \\
\hline Umidade & 6,75 & 11,8 \\
\hline Carboidratos & 82,55 & 75,5 \\
\hline Proteínas & 5,32 & 10,7 \\
\hline Lipídeos & 3,05 & 1,36 \\
\hline Cinzas & 2,33 & 0,64 \\
\hline
\end{tabular}

Fonte: autores.

Após secagem, a farinha do caroço de abacate apresentou um teor de água de $6,75 \%$, considerado baixo, que contribui para conservação. Esse teor de água está de acordo com o que foi determinado pela Agência Nacional de Vigilância Sanitária (ANVISA, 2005), que permite um teor máximo de $15 \%$ de umidade em farinhas. 
O produto também apresentou consideráveis teores de lipídeos (3,05\%), acima do encontrado por Tango et al. (2004) e Melo et al. (2012). No entanto, Rodrigues et al. (2007) relatam valores de 10,91\% de lipídeos no caroço de abacate da variedade Fortuna. A presença de lipídeos no caroço de abacate mostra potencial uso pela indústria alimentícia ou cosmética. Nascimento et al. (2017) relata em seus estudos a possibilidade de se extrair óleo da farinha do caroço de abacate, podendo este ser utilizado na prevenção e tratamento de doenças (WARD, 1995; MAYSER et al., 1998; SANDER, 2000).

O teor de cinzas (2,33\%) caracteriza a presença de minerais no caroço de abacate. Os resultados encontrados no trabalho corroboram com estudos de Melo et al. (2012) e Tango et al. (2004). 0 teor de carboidratos totais (82,55\%) é alto e foi obtido por diferença, sendo uma boa fonte energética. 0 valor encontrado de carboidrato é superior ao mencionado por Tango et al. (2004) e Rodrigues et al. (2007), pelo fato de não excluir os valores de porcentagem de amido, o que não foi quantificado neste trabalho. 0 alto teor de carboidratos apresentado se dá às altas concentrações de fibras alimentares, açúcares e amido presentes no caroço de abacate.

0 teor de proteínas é baixo, quando comparado à farinha de trigo (Tabela 2). Ainda assim, a farinha de caroço de abacate é uma fonte de proteínas e contribui nutricionalmente na formulação de bolos. Em outro estudo, Tango et al. (2005) avaliaram o teor de proteínas em 24 tipos de variedade de abacate e constataram que o teor proteico, dependendo da variedade da fruta, pode variar entre $3,78 \%$ e $6,7 \%$.

\subsection{Análise microbiológica:}

Após a incubação dos tubos em estufa, foi identificado ausência de reação ácida (falta de coloração amarelada) e não houve produção de gás. Dessa forma, não houve crescimento (ausência) de coliformes totais e fecais, indicando que a farinha de abacate é própria para o consumo.

\subsection{Análise do crescimento}

Pode-se observar na Tabela 3 que o bolo padrão cresceu mais que os demais, no entanto, estatisticamente, não houve diferença significativa $(a=0,05)$. Sabe-se que as proteínas da farinha de trigo são as responsáveis pela formação da rede de glúten e estrutura de crescimento do bolo. Dessa forma, esse resultado indicou que a farinha de caroço de abacate não influenciou diretamente no crescimento do bolo, mesmo possuindo um teor de proteína bem inferior ao da farinha de trigo. Esse resultado pode ser explicado pelas baixas porcentagens de farinha de caroço de abacate que foram adicionadas nas formulações propostas pelo trabalho.

Tabela 3 - Tabela da diferença média de altura do bolo na forma antes e depois de assar.

\begin{tabular}{cccc}
\hline \multicolumn{4}{c}{ Diferença na altura do bolo } \\
\hline Bolos & Padrão & Formulação 1 & Formulação 2 \\
\hline 1 & 3,12 & 3,24 & 2,84 \\
\hline 2 & 3,08 & 2,96 & 2,54 \\
\hline 3 & 3 & 3,42 & 3,24 \\
\hline 4 & 3,2 & 2,68 & 2,96 \\
\hline Média & 3,1 & 3,075 & 2,895 \\
\hline
\end{tabular}

Fonte: autores 


\subsection{Análise Sensorial}

A partir dos resultados obtidos na análise sensorial, nota-se que as três formulações foram bem aceitas, com as médias dos pontos hedônicos variando entre 6 e 8, correspondendo desde "gostei ligeiramente" até "gostei muito". A tabela 4 apresenta os resultados da análise sensorial de aceitação do bolo de chocolate, considerando os atributos aparência, aroma, cor, textura e avaliação global.

Tabela 4 -Tabela dos resultados da análise sensorial de aceitação considerando os atributos aparência, aroma, cor, sabor, textura e avaliação global

\begin{tabular}{|c|c|c|c|}
\hline \multirow{2}{*}{ Atributos } & \multicolumn{3}{|c|}{ Formulações } \\
\hline & Padrão (0\%)* & F1 (10\%)* & $\mathrm{F} 2(20 \%) *$ \\
\hline Aparência & $7,53^{a}$ & $7,52^{\mathrm{a}}$ & $7,47^{a}$ \\
\hline Aroma & $7,85^{a}$ & $7,03^{b}$ & $7,40^{\mathrm{ab}}$ \\
\hline Cor & $7,98^{a}$ & $8,00^{a}$ & $7,85^{a}$ \\
\hline Sabor & $7,68^{a}$ & $7,08^{b}$ & $6,45^{c}$ \\
\hline Textura & $7,55^{a}$ & $7,11^{\mathrm{ab}}$ & $6,85^{b}$ \\
\hline Av. global & $7,80^{\mathrm{a}}$ & $7,20^{b}$ & $7,08^{b}$ \\
\hline
\end{tabular}

- Letras diferentes na linha indicam diferenças significativas pelo teste de Tukey $(\alpha<0.05)$

*Porcentagem de farinha do caroço de abacate de cada formulação

Fonte: autores.

Verificamos, através do teste de Tukey, que os atributos de aparência e cor não obtiveram diferença significativa $(a=0,05)$ nas formulações. Já o aroma, o sabor, a textura e avaliação global obtiveram diferença significativa perceptível, mostrando que a formulação padrão foi mais aceita pelos consumidores.

Os testes de análise sensorial das formulações mostraram que a amostra F2, com maior percentual de farinha de caroço de abacate (20\%), foi a menos aceita no atributo sabor, ficando abaixo da amostra padrão e da formulação F1. Segundo Silva et al. (2019), a análise sensorial de biscoitos tipo cookies, com substituição de $20 \%$ de farinha de caroço de abacate, também não tiveram boa aceitação. Os autores reportam que os biscoitos com uma quantidade menor da farinha do caroço de abacate foram mais bem aceitos, o que corrobora com os resultados encontrados. Pode-se observar, na tabela 3 , que o volume do bolo F2 é menor que das outras formulações, ou seja, o bolo de chocolate com substituição de $20 \%$ de farinha de caroço de abacate cresceu menos, o que foi causado pela maior quantidade de gordura presentes na farinha de caroço de abacate. A resposta do crescimento está associada à textura e, consequentemente, ao sabor. Outros autores relataram resultados semelhantes no atributo sabor, nos biscoitos tipo cookies, acrescido com maior porcentagem de farinha de bagaço de uva (PIOVESANA et al., 2013).

Avaliando-se a textura, observa-se que a formulação padrão é maior que F2 e igual a F1, significando um limite de adição da farinha do caroço de abacate, pois o aumento da quantidade dessa farinha impacta na textura do bolo. No entanto, a média dos consumidores não é ruim, ficando entre $6 \mathrm{e}$ 7, ou seja, "gostei moderadamente" e "gostei ligeiramente". Em relação à avaliação global, houve maior aceitação para a formulação padrão e aceitação igual para as formulações F1 e F2, porém ambos são inferiores à formulação padrão, podendo-se observar que foram aceitações globais altas, com médias entre 7 e 8: "gostei moderadamente" e "gostei muito". 


\section{CONCLUSÃO}

O estudo demonstrou que a adição da farinha de caroço de abacate nas formulações promoveu o aumento de valor nutricional para o produto e diminuindo assim o desperdício do caroço e consequente a diminuição do impacto ambiental, podendo favorecer a geração de renda para os empreendedores. A composição centesimal nos mostra que se trata de uma farinha mais rica em nutrientes e lipídeos, devido à característica do fruto. A análise para observar o crescimento do bolo demonstrou que a farinha do caroço não influenciou muito no crescimento, quando comparada com a formulação padrão. Sensorialmente, as formulações apresentaram algumas diferenças nos atributos, sendo o sabor o único atributo em que todas as amostras diferenciaram entre si. Devido às médias dos atributos serem superiores a 6,45, conclui-se que as formulações apresentaram alta aceitabilidade.

O bolo desenvolvido apresentou propriedades sensoriais aceitáveis, demonstrando que os níveis de substituição utilizados foram bem aceitos pelos provadores, sendo um produto com aceitação comercial satisfatória.

\section{BIBLIOGRAFIA}

BRASIL. Agência Nacional de Vigilância Sanitária. Portaria nº 31, de 13 de janeiro de 1998. Disponível em: http://portal.anvisa.gov.br/documents/33916/394219/PORTARIA\%2B_31_1998.pdf/99df1492aeea-4c00-b403-7a5ab8863b9c. Acesso em: 20 out. 2019.

BRASIL. Agência Nacional de Vigilância Sanitária. Resolução RDC n 12/2001, de 02 de janeiro de 2001. Regulamento técnico sobre padrões microbiológicos para alimentos. Disponível em: http://portal.anvisa. gov.br/documents/33880/2568070/RDC_12_2001.pdf/15ffddf6-3767-4527- bfac-740a0400829b. Acesso em: 25 nov. 2020.

BRASIL. Agência Nacional de Vigilância Sanitária. Resolução da Diretoria Colegiada RDC $\mathbf{n}^{\circ}$ 263, de 22 de setembro de 2005. Disponível em: http://portal.anvisa.gov.br/documents/33916/394219/RDC_263_2005. pdf/e9aa3580-f130-4eb5-91cb-8b8818bcf6b2. Acesso em: 10 out. 2019.

BRASIL. Ministério da Agricultura, Pecuária e Abastecimento. Secretaria de Defesa Agropecuária (DISPOA). Instrução Normativa $\mathbf{n}^{\circ}$ 62, de 26 de agosto de 2003. Oficializa os Métodos Analíticos Oficiais para Análises Microbiológicas para Controle de Produtos de Origem Animal e Água. Diário Oficial da União, Brasília, 26 de agosto de 2003. Seção 1.

GUIMARÃES, P. B.; CAPOBIANGO, M. Determinação da composição centesimal de farinha obtida a partir do caroço de abacate. III Congresso Nacional de Alimentos e Nutrição e VI Congresso Nacional de Alimentação e Nutrição, Ouro Preto, 2017.

PADILHA, P.; MEDEIROS, M.; DUARTE, V.; FIGUEIREDO, E.; ABREU P.; ZENEBON, C. Instituto Adolfo Lutz, Métodos Físico-Químicos para Análise de Alimentos. 4. ed e 1. ed. Digital. São Paulo, 2008. Disponível em: http://www.ial.sp.gov.br/resources/editorinplace/ial/2016_3_19/analisedealimentosial_2008. pdf?attach=true. Acesso em: 15 set. 2018.

MAYSER, P.; MROWIETZ, U.; ARENBERGER, P.; BARTAK, P.; BUCHVALD, J.; CRISTHOPHER, E.; JABLONSKA, S.; SALMOHOFER, W.; SCHILL, W.B.; KRAMER, H.J.; SCHLOTZER, E.; MAYER, K.; SEEGER, W.; GRIMMINGER, F. $\omega$-3 fatty acid-based lipid infusion in patients with chronic plaque psoriasis: results of adouble-blind, 
randomized, placedo-controlled, multicenter trial. Journal American Academy of Dermatology, v. 38, n. 4, p.539-547, 1998.

MELO, M. L. N.; COSTA, T. S.; SOUSA, C. A. B; MARSIGLIA, W. I. M. L. Caracterização físico-química do caroço de abacate (Persea americana, Mill). Encontro nacional de educação, ciência e tecnologia, Campina Grande/PB, 2012.

NASCIMENTO, M. R. F.; SOUZA, V. F. de; BOMDESPACHO, L. de Q.; ASCHERI, J. L. R. Perfil de ácidos graxos no óleo extraído das farinhas de caroços de jaca (Artocapus integrifólia L.), abacate (Persea Gratíssima Gaertner F.) e seriguela (Spondias Purpúrea L.). Congresso Brasileiro de engenharia Química em Iniciação Científica, v. 1, n. 4, 2017.

PIOVESANA, A.; BUENO, M. M.; KLAJN, V. M. Elaboração e aceitabilidade de biscoitos enriquecidos com aveia e farinha de bagaço de uva. Brazilian Journal of Food Technology, Campinas, v. 16, n. 1, p. 68-72, 2013.

RORIZ, R. F. C. Aproveitamento dos resíduos alimentícios obtidos das centrais de abastecimento do estado de goiás s/a para alimentação humana. 2012. Dissertação (Mestrado em Ciência e Tecnologia de Alimentos) - Universidade Federal de Goiás, Escola de Agronomia e Engenharia de Alimentos, Goiânia, 2012.

RODRIGUES, J. da S.; LOPES, D.B.; RAMIS-RAMOS, G.; MENDONÇA, C.R.B. Aguacate: características químico-físicas y rendimienti em aceite por extracción com distintos dissolventes. XI Congreso Argentino de Tecnología de Alimentos, Buenos Aires, 2007.

SANDER, T. A. B. Polyunsatured fatty acids in the food chain in Europe. The American Journal of Clinical Nutrition, v. 71, n. 1, p.176-178, 2000.

SARAIVA, S. H.; ZEFERINO, L. B.; JUNQUEIRA, M. S.; SILVA, L. C.; TEIXEIRA, L. J. Q. Avaliação de agentes preservantes do escurecimento enzimático no processo de secagem de maçã. Enciclopedia Biosfera, Centro Científico Conhecer, v. 6, n. 11, p. 1-8, 2010.

SILVA, I. G.; ANDRADE, A. P. C.; SILVA, L. M. R.; GOMES, D. S. Elaboração e análise sensorial de biscoitos tipo cookie feito a partir da farinha do caroço de abacate. Brazilian Journal of Food Technology, Campinas, v. 22, 2019.

SOUZA, A. F., LEÃO, M. F. Análises dos métodos mais eficientes na inibição do escurecimento enzimático em frutas e hortaliças. Enciclopédia Biosfera, Centro Científico Conhecer, v. 8, n. 15, 2012. Disponível em: http://www.conhecer.org.br/enciclop/2012b/ciencias\%20agrarias/analises\%20dos\%20metodos. pdf. Acesso em: 11 out. 2019.

TANGO, J. S.; CARVALHO, C. R. L.; SOARES, N. B. Caracterização física e química e frutos de abacate visando a seu potencial para extração de óleo. Revista Brasileira Fruticultura, Jaboticabal, v. 26, n. 1, 2004.

TBCA USP. Tabela Brasileira de Composição de Alimentos. Universidade de São Paulo. Food Research Center. Versão 6.0. São Paulo, 2017. Disponível em: http://www.tbca.net.br/base-dados/int_composicao_ estatistica.php?cod_produto=C0139A. Acesso em: 11 out. 2019.

WARD, O.P. Microbial production of long-chain PUFAs. Biotechnology Inform, v. 6, p.683-687, 199. 